\title{
General practice funding underpins the persistence of the inverse care law:
}

\author{
cross-sectional study in Scotland
}

\begin{abstract}
\section{Background}

Universal access to health care, as provided in the NHS, does not ensure that patients' needs are met.
\end{abstract}

\section{Aim}

To explore the relationships between multimorbidity, general practice funding, and workload by deprivation in a national healthcare system.

\section{Design and setting}

Cross-sectional study using routine data from 956 general practices in Scotland.

\section{Method}

Estimated numbers of patients with multimorbidity, estimated numbers of consultations per 1000 patients, and payments to practices per patient are presented and analysed by deprivation decile at practice level.

\section{Results}

Levels of multimorbidity rose with practice deprivation. Practices in the most deprived decile had 38\% more patients with multimorbidity compared with the least deprived (222.8 per 1000 patients versus 161.1; $P<0.001$ ) and over $120 \%$ more patients with combined mental-physical multimorbidity (113.0 per 1000 patients versus 51.5; $P<0.001$ ) Practices in the most deprived decile had 20\% more consultations per annum compared with the least deprived ( 4616 versus 3846, $P<0.001$ ). There was no association between total practice funding and deprivation (Spearman $\rho$ $-0.09 ; P=0.03$ ). Although consultation rates increased with deprivation, the social gradients in multimorbidity were much steeper. There was no association between consultation rates and levels of funding.

\section{Conclusion}

No evidence was found that general practice funding matches clinical need, as estimated by different definitions of multimorbidity. Consultation rates provide only a partial estimate of the work involved in addressing clinical needs and are poorly related to the prevalence of multimorbidity. In these circumstances, general practice is unlikely to mitigate health inequalities and may increase them.

\section{Keywords}

consultation rates; funding; general practice; inverse care law; multimorbidity.

\section{INTRODUCTION}

Although the principal social determinants of health operate outside health care, health care can mitigate the effects of poor health, by reducing the severity and delaying the progression of conditions. Whether health care reduces or increases health inequalities depends on the extent to which it is delivered in proportion to need across the socioeconomic spectrum. ${ }^{2}$

The inverse care law states that the availability of good medical care tends to vary inversely with the need for it in the population served. ${ }^{3}$ Throughout the history of the NHS, a major feature of the inverse care law has been the distribution of GPs, in Scotland and in England. .-7 $^{-7}$

Despite the importance of ensuring that resources are allocated in line with the health needs of practice populations, there has been little work analysing the relationships between multimorbidity, general practice resources, workload, and deprivation on a national basis in a complete healthcare system. This study set out to examine these relationships in Scotland, by bringing together multiple datasets aggregated to practice level.

\section{METHOD}

Levels of multimorbidity and consultation rates were calculated from two databases both representative of the Scottish population) by deprivation decile and age

G McLean, PhD, research associate; SW Mercer PhD, FRCGP, professor of primary care research; GCM Watt, MD, FRCGP, FMedSci, FRSE, Norie Miller professor of general practice, General Practice and Primary Care, Institute of Health and Wellbeing, College of Medical, Veterinary and Life Sciences, University of Glasgow, Glasgow.

B Guthrie, PhD, MRCGP, professor of primary care medicine, Quality Safety and Informatics Research Group, Population Health Sciences Division, Medical Research Institute, University of Dundee, Dundee. Address for correspondence

Graham CM Watt, General Practice and Primary group and then applied to general practice populations in 2011-2012.

Deprivation was measured using the 2009 version of the Scottish Index of Multiple Deprivation. Practice deprivation scores were obtained from the Information Services Division (ISD) of NHS Scotland, based on an aggregates of patient postcodes within practices. 8.9 Practice scores were then used to divide practice populations into deciles ( 10 groups of similar population size) from least to most deprived.

Levels of multimorbidity were estimated for general practices in Scotland, using an analysis of data for 40 conditions from 314 representative practices in 2007..$^{10}$ Three definitions of multimorbidity were used: two or more chronic conditions, five or more chronic conditions, and combinations of physical and mental conditions. Prevalence rates were calculated for age groups $(0-24$, $25-44,45-64,65-74,75-84$, and $\geq 85$ years) for each decile of deprivation and the resulting age and deprivation specific rates for deciles applied to practice populations for 2012.

The same process was followed for consultation rates, which were calculated from Practice Team Information (PTI) data from ISD Scotland for 2011-2012, based on data from 60 general practices, which are broadly representative of the Scottish population in terms of age, sex, deprivation, and urban/rural mix."

Care, Institute of Health and Wellbeing, College of Medical, Veterinary and Life Sciences, University of Glasgow, 1 Horselethill Road, Glasgow G12 9LX, UK. E-mail: Graham.Wattaglasgow.ac.uk

Submitted: 3 July 2015; Editor's response: 11 August 2015; final acceptance: 15 September 2015

\section{CBritish Journal of General Practice}

This is the full-length article (published online 30 Nov 2015) of an abridged version published in print. Cite this article as: Br J Gen Pract 2015; DOI: 10.3399/bjgp15X687829 


\begin{abstract}
How this fits in
The ability of general practice to reduce the severity and slow the progression of established conditions depends not only on universal coverage but also the ability to respond to patients' needs. This overview of a national general practice system, within the UK NHS, shows steep social gradients in mortality and multimorbidity associated with a generally flat distribution of practice funding. Consultation rates are a limited measure of clinical need, with a much shallower social gradient than the prevalence of multimorbidity. General practice funding underpins the persistence of the inverse care law and its contribution to continuing inequalities in health.
\end{abstract}

Because of the smaller volume of PTI data, consultation rates were only available for quintiles of deprivation. Therefore, rates for quintiles to deciles were applied, so the consultation rates for quintile 1 were given to deciles 1 and 2, quintile 2 to deciles 3 and 4 , and so on.

Standardised mortality rates for individuals aged $<75$ years were obtained from ISD Scotland based on 2004 figures, which was the last year when these data were released at practice level. ${ }^{5}$

Payments to practices for the financial year 2011-2012 were obtained from Practitioner Services. ${ }^{12}$ Total funding for practices was compared, before and after excluding the correction factor payment lalso called the minimum practice income guarantee [MPIG], which was used to topup practice core funding to match basic income levels before the introduction of the new general medical services [GMS] contract), and also after excluding practices classified as remote and very remote by the Scottish Executive Urban Rural Classification (SEURC), ${ }^{13}$ as remote practices receive additional funding to ensure practice viability in remote areas with low populations. ${ }^{14}$ Payments were combined into three categories: essential services Iglobal sum capitation, correction factor, section 17c payments, doctors retainer scheme, seniority, golden hello payments, locums, and payments for premises); enhanced service (ES) payments lpayments for providing additional noncore services such as anticoagulation monitoring); and Quality and Outcomes Framework payments IQOF, pay-forperformance). ${ }^{14}$

Analysis was restricted to practices with no missing data, leaving 956 practices in total $196.5 \%$ of all Scottish general practices). Mean practice scores were calculated by deprivation deciles for all variables. Regression analysis was used to examine associations between funding (total pay per patient) and multimorbidity, mortality, and consultation rates reporting both unadjusted and adjusted Ideprivation, rurality, practice list size, and

\section{Table 1. Number and health characteristics of 956 Scottish general practices}

\begin{tabular}{|c|c|c|c|c|c|c|c|c|c|c|}
\hline Deprivation decile & $\begin{array}{l}\text { Mean } \\
\text { SIMD } \\
\text { score }\end{array}$ & $\begin{array}{c}\text { Practices, } \\
n\end{array}$ & Population & $\begin{array}{c}\text { Mean } \\
\text { practice } \\
\text { population }\end{array}$ & $\begin{array}{l}\text { Patients } \\
\text { aged } \\
\geq 75 \text { years, } \\
\%\end{array}$ & $\begin{array}{l}\text { Standardised } \\
\text { mortality ratio } \\
\text { aged }<75 \text { years }\end{array}$ & $\begin{array}{c}\text { Patients } \\
\text { with MM } \geq 2 \\
\text { conditions per } \\
\text { 1000, } n\end{array}$ & $\begin{array}{l}\text { Patients with mixed } \\
\text { mental-physical health } \\
\text { conditions per } 1000 \\
\text { registered, } n\end{array}$ & $\begin{array}{c}\text { Patients with } \geq 5 \\
\text { conditions per } \\
1000 \\
\text { registered, } n\end{array}$ & $\begin{array}{c}\text { Mean } \\
\text { consultations } \\
\text { per } 1000 \\
\text { patients }\end{array}$ \\
\hline 1 - least deprived & 4.5 & 84 & 531416 & 6326 & 8.5 & 61.8 & 161.1 & 51.5 & 25.1 & 3846 \\
\hline 2 & 7.9 & 110 & 538022 & 4890 & 8.7 & 77.1 & 164.0 & 52.4 & 24.1 & 3927 \\
\hline 3 & 10.7 & 99 & 524745 & 5300 & 8.6 & 85.6 & 185.5 & 59.1 & 28.9 & 4026 \\
\hline 4 & 13.3 & 91 & 533919 & 5867 & 8.2 & 91.7 & 190.9 & 65.4 & 29.5 & 4058 \\
\hline 5 & 16.5 & 91 & 531095 & 5836 & 8.0 & 96.1 & 206.8 & 75.4 & 34.0 & 4365 \\
\hline 6 & 19.9 & 89 & 527378 & 5926 & 8.2 & 99.3 & 197.8 & 76.2 & 33.4 & 4239 \\
\hline 7 & 23.8 & 88 & 527302 & 5992 & 7.6 & 105.7 & 200.4 & 79.9 & 32.6 & 4464 \\
\hline 8 & 29.8 & 95 & 533663 & 5618 & 7.3 & 115.4 & 219.0 & 88.9 & 41.9 & 4436 \\
\hline 9 & 39.3 & 91 & 530384 & 5828 & 6.9 & 120.2 & 207.3 & 91.5 & 37.5 & 4631 \\
\hline $10-$ most deprived & 62.8 & 118 & 524844 & 4448 & 6.1 & 149.4 & 222.8 & 113.0 & 48.5 & 4616 \\
\hline Total & & 956 & 5302768 & - & - & - & - & - & - & - \\
\hline Scotland mean & 22.5 & 96 & 530276 & 5547 & 7.8 & 100 & 195.5 & 75.2 & 33.5 & 4266 \\
\hline $\begin{array}{l}\text { Total pay per } \\
\text { patient, URC }\end{array}$ & - & - & - & - & - & $\begin{array}{c}0.001 \\
(P<0.001)\end{array}$ & $\begin{array}{c}0.004 \\
(P<0.001)\end{array}$ & $\begin{array}{c}0.003 \\
(P<0.001)\end{array}$ & $\begin{array}{c}0.002 \\
(P<0.001)\end{array}$ & $\begin{array}{c}0.03 \\
(P<0.001)\end{array}$ \\
\hline $\begin{array}{l}\text { Total pay per } \\
\text { patient, ARC }\end{array}$ & - & - & - & - & - & $\begin{array}{c}0.003 \\
(P<0.001)\end{array}$ & $\begin{array}{c}0.004 \\
(P<0.001) \\
\end{array}$ & $\begin{array}{c}0.006 \\
(P<0.001)\end{array}$ & $\begin{array}{c}0.005 \\
(P<0.001)\end{array}$ & $\begin{array}{c}0.03 \\
(P<0.001)\end{array}$ \\
\hline
\end{tabular}

Regression adjusted analysis by deprivation, list size, rurality, and age distribution of practice. $A R C=$ adjusted regression coefficient. MM = multimorbidity. SIMD = Scottish Index of Multiple Deprivation. URC = unadjusted regression coefficient. 


\section{Table 2. Mean ( $\mathrm{f}$ ) total funding per patient to practices by deprivation decile}

\begin{tabular}{|c|c|c|c|c|c|c|}
\hline Deprivation decile & $\begin{array}{l}\text { Total contract } \\
\text { payments, mean } \\
\text { (SD) £ per patient }\end{array}$ & $\begin{array}{l}\text { Difference from } \\
\text { least deprived } \\
\text { decile, } € \text { per patient }\end{array}$ & $\begin{array}{l}\text { Total contract payments } \\
\text { minus correction factor } \\
\text { payments, mean (SD) } \\
\text { £ per patient }\end{array}$ & $\begin{array}{l}\text { Difference from } \\
\text { least deprived } \\
\text { decile, } € \text { per patient }\end{array}$ & $\begin{array}{l}\text { Total contract payments } \\
\text { excluding remote and very } \\
\text { remote practices, }{ }^{a} \text { mean } \\
\text { (SD) } € \text { per patient }\end{array}$ & $\begin{array}{l}\text { Difference from } \\
\text { least deprived } \\
\text { decile, } € \text { per patient }\end{array}$ \\
\hline $1-$ least deprived & 111.51 (26.2) & - & 108.09 (20.2) & - & 107.80 (14.9) & - \\
\hline 2 & 142.57 (61.7) & $31.06(P<0.01)$ & 131.18 (41.4) & $25.09(P<0.01)$ & 120.14 (24.1) & $12.34(P<0.01)$ \\
\hline 3 & 126.65 (42.3) & $15.14(P=0.01)$ & $119.10(29.4)$ & $11.01(P=0.01)$ & 111.68 (18.4) & $3.88(P=0.20)$ \\
\hline 4 & $120.36(28.6)$ & $8.85(P=0.13)$ & $115.29(22.6)$ & $7.20(P=0.13)$ & 112.10 (14.0) & $4.30(P=0.34)$ \\
\hline 5 & 133.66 (51.3) & $22.15(P<0.01)$ & 128.16 (45.2) & $20.06(P<0.01)$ & $115.64(16.9)$ & $7.84(P=0.01)$ \\
\hline 6 & $126.90(48.6)$ & $15.39(P<0.01)$ & $119.78(38.1)$ & $11.69(P=0.01)$ & 115.37 (19.5) & $7.57(P=0.04)$ \\
\hline$\overline{7}$ & 117.38 (28.8) & $5.87(P=0.31)$ & $115.01(28.9)$ & $6.92(P=0.14)$ & $112.93(17.5)$ & $5.13(P=0.09)$ \\
\hline 8 & $114.57(19.6)$ & $3.06(P=0.60)$ & $112.68(19.7)$ & $4.58(P=0.34)$ & 114.14 (19.7) & $6.34(P=0.04)$ \\
\hline 9 & 116.22 (15.2) & $4.71(P=0.42)$ & $113.42(14.0)$ & $5.33(P=0.27)$ & 115.02 (15.1) & $7.21(P=0.01)$ \\
\hline 10 - most deprived & $120.43(20.7)$ & $8.92(P=0.10)$ & 117.45 (20.2) & $9.36(P=0.04)$ & $121.65(20.7)$ & $13.85(P<0.01)$ \\
\hline Scotland mean & 123.32 (38.40) & - & $118.07(30.40)$ & - & 115.52 (25.79) & 123.32 (38.40) \\
\hline Spearman $\rho$ & -0.09 & $P=0.03$ & 0.04 & $P=0.13$ & 0.07 & $P=0.09$ \\
\hline
\end{tabular}

${ }^{a}$ Remote and very remote practices based on Scottish Executive Urban rural classification, defined as those between 30 and 60 minutes (remotel or $>60$ minutes (very remotel drive-time from an urban area of $>10000$ people.

age distribution of practice). Spearman rank correlations were used to examine associations between types of payment and deprivation

\section{RESULTS}

Although population size was broadly equal across deciles, larger numbers of practices were found in decile 2 and in the most deprived decile, indicating the numbers of small practices in these deciles (Table 1). The more deprived practices had a smaller percentage of patients aged $\geq 75$ years (most deprived $6.1 \%$ versus least deprived $8.5 \%, P<0.001$ ) (Table 1).

All-cause mortality in patients $<75$ years increased 2.4-fold from the least to the most deprived population decile (Table 1). Practices in the most deprived decile also had, on average, $38 \%$ more patients with two or more conditions (most deprived 222.8 per 1000 patients versus least deprived 161.1; $P<0.001$ ); $124 \%$ more patients with combined mental-physical multimorbidity (113.0 per 1000 patients versus 51.5; $P<0.001)$ and $93 \%$ more patients with five or more conditions (most deprived 48.5 per 1000 patients versus least deprived 25.1; $P<0.001$ )

Consultation rates showed a clear association with deprivation, with the most deprived decile having 20\% more consultations per 1000 patients lmost deprived decile 4616 versus least deprived 3846; $P<0.001$. Regression analysis showed only marginal increases in funding with a unit increase for all variables. The strongest association was reported for consultations

Table 3. Mean total funding per patient for individual categories by deprivation decile

\begin{tabular}{|c|c|c|c|c|c|c|}
\hline Deprivation decile & $\begin{array}{c}\text { Essential contract } \\
\text { payments, mean (SD), } \\
\text { € per patient }\end{array}$ & $\begin{array}{c}\text { Difference from least } \\
\text { deprived decile, } \\
\text { £ per patient }\end{array}$ & $\begin{array}{c}\text { QOF contract } \\
\text { payments, mean (SD), } \\
\text { £ per patient }\end{array}$ & $\begin{array}{c}\text { Difference from least } \\
\text { deprived decile, } \\
\text { £ per patient }\end{array}$ & $\begin{array}{c}\text { Enhanced contract } \\
\text { payments, mean (SD), } \\
\text { £ per patient }\end{array}$ & $\begin{array}{c}\text { Difference from least } \\
\text { deprived decile, } \\
\text { £ per patient }\end{array}$ \\
\hline 1 - least deprived & $84.78(24.7)$ & - & $22.3(3.1)$ & - & $4.34(1.9)$ & - \\
\hline 2 & $114.85(61.4)$ & $30.1(P<0.001)$ & 23.50 (3.3) & $1.13(P=0.01)$ & $4.20(1.6)$ & $-0.13(P=0.58)$ \\
\hline 3 & $98.33(41.4)$ & $13.6(P=0.01)$ & $24.02(3.6)$ & $1.64(P=0.01)$ & $4.28(1.7)$ & $-0.06(P=0.81)$ \\
\hline 4 & 91.19 (27.2) & $6.4(P=0.23)$ & $24.97(2.6)$ & $2.61(P<0.001)$ & $4.18(1.3)$ & $-0.16(P=0.51)$ \\
\hline 5 & $104.39(51.2)$ & $19.6(P=0.01)$ & 25.04 (2.5) & $2.66(P<0.001)$ & $4.22(1.4)$ & $-0.12(P=0.63)$ \\
\hline 6 & 97.47 (47.2) & $12.7(P=0.02)$ & 25.27(3.2) & $2.89(P<0.001)$ & $4.14(2.0)$ & $-0.19(P=0.42)$ \\
\hline 7 & 89.95 (28.5) & $4.2(P=0.46)$ & $24.3(3.3)$ & $2.05(P<0.001)$ & $4.00(1.4)$ & $-0.35(P=0.15)$ \\
\hline 8 & 85.29 (18.9) & $0.51(P=0.92)$ & 25.28 (3.0) & $2.91(P<0.001)$ & $3.98(2.0)$ & $-0.36(P=0.15)$ \\
\hline 9 & $86.69(13.7)$ & $1.89(P=0.74)$ & 25.67 (3.3) & $3.29(P<0.001)$ & $3.86(1.6)$ & $-0.47(P=0.06)$ \\
\hline 10 - most deprived & 91.12 (19.4) & $6.3(P=0.24)$ & $25.98(3.0)$ & $3.59(P<0.001)$ & $3.32(1.1)$ & $-1.01(P<0.001)$ \\
\hline Scotland mean & $94.58(37.7)$ & - & $24.70(3.26)$ & - & $4.03(1.6)$ & - \\
\hline Spearman $\rho$ & -0.10 & $P=0.01$ & 0.27 & $P<0.001$ & -0.17 & $P<0.001$ \\
\hline
\end{tabular}

QOF $=$ Quality and Outcomes Framework. 


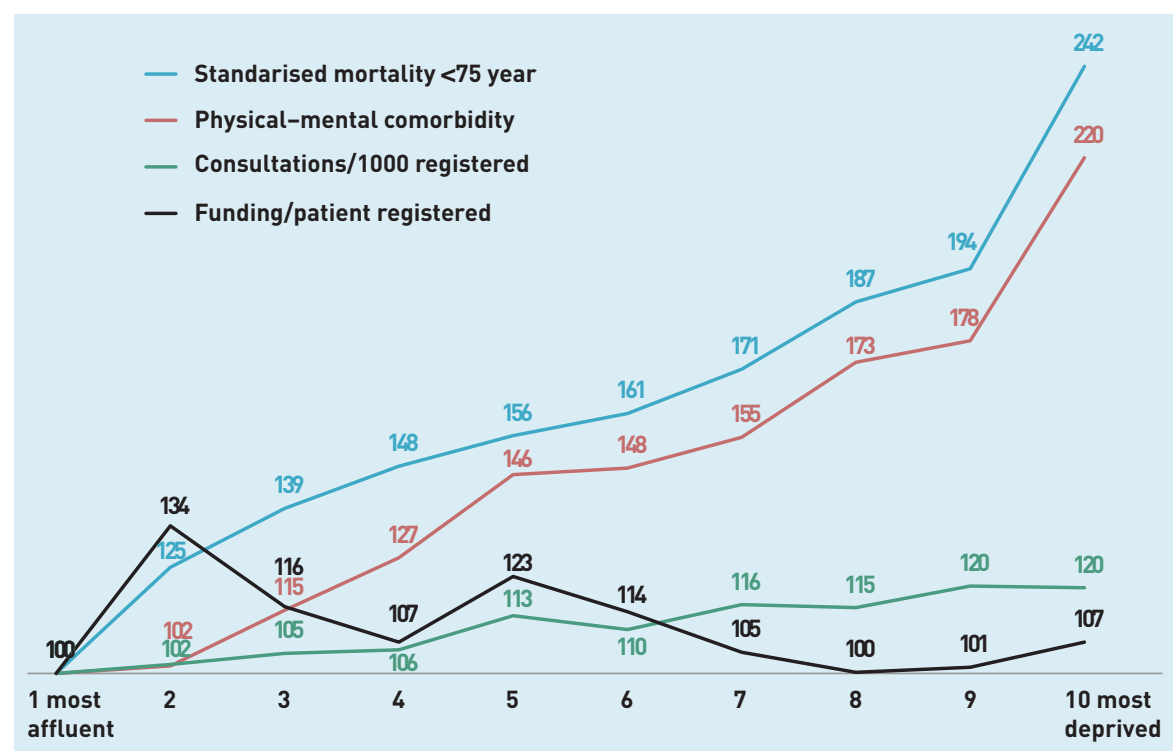

Figure 1. \% Differences from least deprived decile for mortality, comorbidity, consultations, and funding. Least deprived decile $=100$. in total payments being broadly flat across deciles (Spearman $\rho-0.10 ; P=0.01$ ).

The rise in consultation rates with increasing deprivation was considerably less pronounced than the increase in multimorbidity. Figure 1 shows the percentage differences for deprivation deciles, compared with the least deprived (with least deprived decile adjusted to = 100) for a selection of variables.

\section{DISCUSSION}

\section{Summary}

General practice populations in the most deprived areas have much higher levels of premature mortality and multimorbidity. When multimorbidity is defined as the presence of two or more chronic conditions, however, the combination may not involve complexity ffor example, the most common combination is hypertension and one other condition). Multimorbidity was also defined in ways implying greater clinical need, such as five or more chronic conditions, and the combination of physical and mental conditions. In both these cases there was a much steeper social gradient, similar to the gradient in mortality, with twice as much multimorbidity in the most deprived decile of practices as in the least deprived. Although GPs in deprived areas carry out more consultations than GPs in other areas, the social gradient in consultation rates is less steep than the social gradients in multimorbidity and mortality. The present findings provide no evidence that funding or clinical activity matches clinical need.

\section{Strengths and limitations}

Findings from a complete national health system are presented, comprising 956 general practice populations, all of which could be characterised by age, sex, and deprivation, based on postcodes and deprivation scores for all patients. The present assessment of practice resources based on practice funding is an improvement on previous studies of the inverse care law comparing whole-time equivalent (WTE) numbers of practitioners. ${ }^{5}$ The most recent complete data on GP WTE numbers pre-date the new GMS contract and are increasingly out of date. Practice funding provides a better indication of the total resource available for general practice services, including the employment of GPs, nurses, and other staff, premises, and other running costs.

The present estimates of multimorbidity and consultation rates are based on data from samples of $314(31 \%)$ and 60 (6\%) practices, respectively. Their combined list 
populations are large and representative of the general Scottish population in terms of demography and deprivation. To measure multimorbidity, 40 morbidities were used including several that are not generally included in multimorbidity studies but have a major impact on a patient's quality of life and feature prominently in the work of general practice. ${ }^{10}$ Although different deprivation measures were used to categorise multimorbidity (based on the Carstairs score) and consultations (based on SIMD), there is a strong correlation between these scores. Only a small number of practices change decile using either scoring system and the results would be similar in either case.

Multimorbidity levels are calculated from 2007 and applied to practice populations in 2012, when data on consultation rates and practice funding also were available. The resulting estimates of multimorbidity prevalence in 2011-2012 may be imprecise, but it is unlikely that the observed social gradients changed sufficiently to have a significant effect on the findings. This study presents a pragmatic, composite picture, describing the realities of general practice in Scotland.

\section{Comparison with existing literature}

The authors are not aware of similar data elsewhere to allow comparison between health systems. The principal findings of the present study are that neither general practice funding nor the amount of clinical activity, in terms of number of consultations, are closely aligned with social gradients in multimorbidity and mortality.

In the UK general practices receive income via the GMS contract, with separate funding streams for essential services, the QOF, and ES. ${ }^{14}$ Although a significant proportion of practices have alternative locally negotiated contracts Ipersonal medical services in England and Wales, section 17c and section 2c contracts in Scotland), these are usually based on the GMS model unless the practice serves a particular population such as homeless people.

About two-thirds of general practice funding in the UK is provided via the global sum, which is similar in design but differs in detail across the UK jurisdictions. ${ }^{14}$ In Scotland, the Scottish Allocation Formula (SAF) determines how the global sum is distributed between practices. ${ }^{15}$ Payments per registered patient under SAF are determined by the age and sex structure of the practice population (with weightings determined by estimated consultation rates, based on PTI data from 2004- 2005); additional needs of the practice population (morbidity and deprivation); and rurality and remoteness of the practice population. Other weights, taking account of the workloads generated by care home patients and new registrations, are set at a UK level but have a smaller effect. A further adjustment allows for differences in staff costs between Scottish health board areas.

Despite weighting for deprivation, practice funding remains broadly flat as deprivation increases in the population. A possible explanation is the weighting given in the SAF for rurality and remoteness, to ensure the viability of small practices serving sparsely populated areas. ${ }^{13}$ Rural and remote practices are generally located in less deprived deciles (for example, decile 2) and receive around twice as much funding per patient than practices located in primary cities in Scotland. Rural and remote practices only make up a small proportion of all Scottish practices, however, and if these practices are excluded, the analysis produces similar results (Table 2).

Changes to the way the global sum is allocated were proposed in the UK in 2014-2015, ${ }^{16}$ including the removal of the MPIG. Removing such payments from this analysis (Table 2 ) reduces the funding to all practices, especially practices in affluent areas, but makes little difference to the overall results lalthough some individual practices will experience very large changes). Similarly, although QOF payments increase with deprivation, because the prevalence of chronic disease is higher in more deprived practices, the overall effect on practice income is small.

Recent changes to the global sum in England have increased the weighting given to older patients, in response to the increasing numbers of such patients and their higher use of services. ${ }^{16}$ Government proposals to drop the weighting for deprivation, thereby enhancing the effect of weighting by age, were rejected by NHS England, however, in favour of a funding formula with the aim of targeting unmet need in deprived areas. ${ }^{17}$ Critics of the new formula questioned whether it will achieve that effect. ${ }^{18,19}$ Evidence from this study shows that although practices in more deprived areas have younger populations, they also have higher levels of multimorbidity, occurring at a much younger age, and will be disadvantaged by allocation formulas where age is given such prominence.

These issues reflect the difficulty of assessing and comparing the clinical 


\section{Funding}

Chief Scientist Office of the Scottish Government Health Directorates (Applied Research Programme Grant ARPG/07/1).

\section{Ethical approval}

Ethical approval was not required for this study of anonymised data.

\section{Provenance}

Freely submitted; externally peer reviewed.

\section{Competing interests}

The authors have declared no competing interests.

\section{Acknowledgements}

We thank the Scottish School of Primary Care, which part supported Stewart W Mercer's post and the development of the Applied Research Programme; and the Primary Care Clinical Informatics Unit at the University of Aberdeen, which provided the data contained herein. The views in this publication are not necessarily the views of the University of Aberdeen, its agents, or employees. We thank Katie Wilde and Fiona Chaloner of the University of Aberdeen, who did the initial data extraction and management.

\section{Discuss this article}

Contribute and read comments about this article: bjgp.org/letters

needs and demands of patients with and without longevity. Practices in more affluent populations have higher numbers of frail older patients (Table 1), who are less mobile, have multiple medical and care needs, and are more likely to require coordinated care, including home visits. Practices in very deprived areas have larger numbers of patients with combined physical, mental, and social morbidities, particularly in younger age groups, who need more time for engagement, and for steadily working through their problems. All practices are busy with different combinations of needs and demands, with different implications for population health and longevity.

Crude comparisons of consultation rates do not capture these different aspects of practice. ${ }^{20}$ The consultation data in this study include patient encounters with GPs and practice nurses, and home visits, but provide no information on the variable duration, content, and quality of encounters, the extent to which they reflect needs and/ or demands, nor the increasing amount of administrative work required before and after consultations.

However, it is noteworthy that the social gradient in consultation rates is less steep than the social gradients in multimorbidity and mortality. With a flat distribution of funding, deprived practices can only generate increased consultation rates by having shorter consultation times, or working longer hours. A study of 3000 consultations in general practice in the West of Scotland described the practical consequences for patients and practitioners. Consultations in deprived areas involve higher levels of multimorbidity and social complexity, shorter duration, lower expectations, less patient enablement, especially for patients with mental health problems, and higher practitioner stress. ${ }^{21}$ Basing funding on consultation rates simply institutionalises the inverse care law, to the detriment of the most vulnerable patients with complex problems. ${ }^{22-24}$

\section{Implications for practice}

Universal healthcare coverage provides access to care, but does not in itself equip front-line practitioners to respond proportionately to patients' clinical needs. On average, GPs in more deprived areas have a higher workload, with more consultations with patients who are more likely to be multimorbid with both physical and mental conditions, but do not receive additional funding to address these complex needs.

When needs are partially met, the heath service underachieves in reducing the severity and slowing the progression of health and social problems. Until allocation formulas in Scotland and the rest of the UK take into account the earlier onset of morbidity in more deprived areas and the wide deprivation-related differences in multimorbidity and chronic illness between age groups, such funding systems will remain inequitable, and continue to be part of the problem of health inequalities, rather than part of the solution. 


\section{REFERENCES}

1. Starfield B. Contributions of evidence to the struggle towards equity. John Fry Fellowship Lecture. Nuffield Trust: Nuffield Trust For Research and Policy Studies in Health Services, 2004

2. Barr B, Bambra C, Whitehead M. The impact of NHS resource allocation policy on health inequalities in England 2001-11: longitudinal ecological study. BMJ 2014; 349: g3231.

3. Hart JT. The inverse care law. Lancet 1971; 297: 405-412.

4. Watt $G$. The inverse care law today. Lancet 2002; 360: 252-254.

5. Mackay D, Sutton M, Watt G. Deprivation and volunteering by general practices: cross-sectional analysis of a national primary care system. BMJ 2005; 331: 1449-1451.

6. Hann M, Gravelle $H$. The misdistribution of general practitioners in England and Wales: 1974-2003. Br J Gen Pract 2004; 54: 894-898.

7. National Audit Office. Tackling inequalities in life expectancy in areas with the worst health and deprivation. National Audit Office, London, 2012. http://wnw.nao. org.uk/wp-content/uploads/2010/07/1011186.pdf laccessed 21 October 2015).

8. GMS statement of financial entitlements. http://www.sehd.scot.nhs.uk/pca/ PCA2012\%28M\%2913.pdf laccessed 21 Oct 2015).

9. Mclean G, Guthrie B, Watt G, Gabbay M, O'Donnell C. Practice postcode versus patient population: a comparison of data sources in England and Scotland. Int J Health Geogr 2008; 7: 37.

10. Barnett K, Mercer SW, Norbury M, et al. Epidemiology of multimorbidity and implications for health care, research, and medical education: a cross-sectional study. Lancet 2012; 380: 37-43.

11. Information Services Division Scotland. GP consultations / practice team information (PTI) statistics, 2013. http://www.isdscotland.org/Health-Topics/ General-Practice/GP-Consultations/ (accessed 21 Oct 2015).

12. Practitioner Services Scotland. http://umw.psd.scot.nhs.uk/ laccessed 21 Oct 2015).
13. The Scottish Government. Scottish government urban rural classification, 2014. http://uww.scotland.gov.uk/Topics/Statistics/About/Methodology/ UrbanRuralClassification (accessed 21 Oct 2015).

14. NHS Employers. GMS finance. http://www.nhsemployers.org/your-workforce/ primary-care-contacts/general-medical-services/gms-finance laccessed $280 \mathrm{ct}$ 2015).

15. Information Services Division Scotland. The resource allocation formula in Scotland, 2014. http://unw.isdscotland.org/Health-Topics/Finance/ResourceAllocation-Formula/ laccessed 21 Oct 2015).

16. NHS Employers. GMS contract changes. http://www.nhsemployers.org/yourworkforce/primary-care-contacts/general-medical-services/gms-contractchanges laccessed 28 Oct 2015).

17. NHS England. 'We must tackle health inequalities' says NHS England's chief financial officer, 2013. http://www.england.nhs.uk/2013/12/18/tackle-healthinequalities/ (accessed 21 Oct 2015).

18. Limb M. Doctors object to CGG funding formula that emphasises age over deprivation. BMJ 2013; 346: f7175.

19. Barr B, Taylor-Robinson D. Poor areas lose out most in new NHS budget allocation. BMJ 2014; 348: g160.

20. Watt G. Discretion is the better part of general practice. Br J Gen Pract 2015; 65: 306

21. Mercer $\mathrm{S}$, Watt $\mathrm{G}$. The inverse care law: clinical primary care encounters in deprived and affluent areas of Scotland. Ann Fam Med 2007; 5: 503-510.

22. Mercer SW, Gunn J, Bower P, et al. Managing patients with mental and physical multimorbidity. BMJ 2012; 345: e5559.

23. Mercer SW, Guthrie B, Furler J, et al. Multimorbidity and the inverse care law in primary care. BMJ 2012; 344: e4152.

24. Baker M, Mawby R, Ware J. Health inequalities. London: Royal College of General Practitioners, 2015. http://www.rcgp.org.uk/policy/rcgp-policy-areas/ / media/Files/Policy/A-Z-policy/2015/Health\%20Inequalities.ashx laccessed 21 Oct 2015). 